\title{
"TODA BOA, TODA BOA, ELA É TODA BOA": SOBRE O ESTEREÓTIPO MIDIÁTICO DA MULHER BRASILEIRA NO IMAGINÁRIO PORTUGUÊS
}

\author{
Simone Formiga \\ PUC-Rio \\ simone.formiga@infolink.com.br \\ Heitor Alvelos \\ Faculdade de Belas-Artes da Universidade do Porto - FBAUP, Portugal \\ halvelos@fba.up.pt \\ Luiz Antonio Coelho \\ PUC-Rio \\ urbanosantos@terra.com.br
}

Resumo: A pesquisa investiga que propósitos o estereótipo da mulher brasileira, representado em contextos midiáticos portugueses, busca atender. Parte do pressuposto de que essas representações servem como um mecanismo simbólico de contraste perante uma ideia de virtude que se pretende conferir à mulher portuguesa e confirma o pressuposto assumido. Tem como objetivo principal contribuir para uma leitura mais eficaz de representações midiáticas, desenvolvendo um mecanismo de interpretação do universo imagético, buscando, assim, consolidar um conjunto de meios de decodificação de imagens. A metodologia desenvolvida foi baseada no pensamento de Panofsky, especificamente na classificação que o autor propõe dos níveis de interpretação de uma imagem (pré-iconográfico, iconográfico e iconológico) e no conceito de habitus de Bourdieu - "a identidade social define-se e afirma-se na diferença". Foram analisadas vinte e duas páginas, doze páginas da revista Focus e dez páginas da revista Sábado, durante o período de setembro de 2010 a março de 2011. Foram encontradas vinte e seis imagens de atrizes/celebridades brasileiras, mas como algumas se repetem, são apenas vinte as atrizes/celebridades representadas.

Palavras-chave: design editorial, imaginário português, estereótipo da mulher brasileira
Abstract: The research investigates and tries to understand the intentions of the stereotype created about Brazilian women, represented in contexts of Portuguese media. The assumption that these representations serve as a symbolic mechanism of contrast with the idea of virtue that is intended to be attributed to Portuguese woman is confirmed. Its main objective is to contribute to a more effective reading of media representations, developing a mechanism of interpretation of imaging universe, seeking to consolidate 
a set of means that facilitates the decoding of images. The developed methodology was based on the Panofsky's thought, specifically, in his classification of levels of interpretation of an image (pre-iconographic, iconographic and iconological) and in the Bourdieu's concept of habitus "The social identity is defined and exist in the difference". Were analyzed twenty-two pages: twelve of the Focus's magazine and ten of Sabado's magazine, during the period of September 2010 to March 2011. There were found twenty-six images of actresses/Brazilian celebrities but, as some are repeated, only twenty actresses/celebrities are represented.

Keywords: editorial design, imaginary Portuguese, Brazilian women stereotype

\section{INTRODUÇÃO}

Este trabalho é o resultado da tese de doutoramento intitulada: representações nas vossas cabeças: sobre as representações midiáticas do estereótipo da mulher brasileira que habita o imaginário português. A pesquisa foi desenvolvida e defendida no Departamento de Design da Faculdade de Belas Artes da Universidade do Porto

O objetivo da investigação foi contribuir para uma leitura mais eficaz de representações midiáticas, desenvolvendo um mecanismo de interpretação do universo imagético, buscando, assim, consolidar um conjunto de meios de decodificação de imagens. Nosso objetivo foi atingido, pois acabamos por desenvolver uma metodologia baseada nos três níveis de leitura de uma imagem propostos por Panofisky: pré-iconográfico, iconográfico e iconológico. A teoria muito nos auxiliou na elaboração das categorias de análise das imagens pertencentes ao corpus.

Partimos do conceito de Luciana Pontes acerca do estereótipo da mulher brasileira que habita o imaginário português. Segundo a autora, a imagem da mulher brasileira acaba por ser constituída por atributos de "brasilidade", que estão relacionados com a etnicidade e a morenidade. No imaginário português a mulher brasileira é considerada alegre, fácil e quente na cama.

\section{DESENVOLVIMENTO}

\subsection{0 estado da arte}

Baseada no conceito de Pierre Bourdieu (2008), que diz serem os(as) designers intermediários(as) culturais e, como tal, produtores(as) de bens simbólicos; na afirmação de Mike Featherstone (1995): "enquanto intermediários culturais, eles desempenham um papel importante na educação do público para novos gostos e estilos" e no entendimento de Lippmann quando conceitua o termo estereótipo como "as representações nas nossas cabeças" a pesquisa buscou identificar a que propósitos serve o estereótipo da mulher brasileira representado em contextos midiáticos portugueses pertencentes ao imaginário português.

A hipótese da pesquisa foi confirmada. Estabelecia que as representações midiáticas do estereótipo da mulher brasileira presente no imaginário português servem, também, como um mecanismo simbólico de contraste perante uma 
virtuosidade que se pretende atribuir à mulher portuguesa. Pudemos, ao longo da investigação, verificar uma hipersexualização da mulher brasileira em suas representações que, comparadas às representações de mulheres portuguesas, acabam por confirmar a nossa hipótese.

O ponto de partida da pesquisa deu-se em função de uma primeira análise de imagens de mulheres brasileiras estampadas em páginas de revistas generalistas portuguesas (reconhecidas como noticiosas no Brasil), que foram comparadas a imagens de mulheres portuguesas estampadas nas mesmas páginas. A partir das comparações iniciais, começamos a perceber uma grande diferença na produção das imagens produzidas no Brasil e em Portugal e intuímos que as representações midiáticas do estereótipo da mulher brasileira, presente no imaginário português, poderiam servir como um mecanismo simbólico de contraste perante uma virtude atribuída, historicamente, à mulher portuguesa, que foi determinada pelo regime salazarista. A mulher portuguesa, na época de Salazar, foi educada e preparada para abdicar da sua vida pessoal e da sua sexualidade em prol do marido, dos filhos, da família e do bem estar da sociedade portuguesa.

No entanto, no decorrer da investigação, começamos a perceber que "o modo de ser brasileiro" estava a ser divulgado como "copiável e aplicável". As características de brasilidade representadas pelas imagens nas revistas, pelas novelas brasileiras transmitidas pelas redes de televisão portuguesas, pelas peças publicitárias que anunciavam produtos ou serviços brasileiros, entre outras variáveis, estavam a "vender" novas possibilidades. Um bom exemplo disso é o caso de um ginásio (academia no Brasil) que prometia "deixar o seu 'bum bum' em forma para o verão" ou dizia "o segredo das brasileiras agora é seu!". Este discurso enaltecia uma "bunda dura e empinada" como uma característica de brasilidade a ser apropriada pela mulher portuguesa e conseguida através de um programa de exercícios físicos específicos para tal.

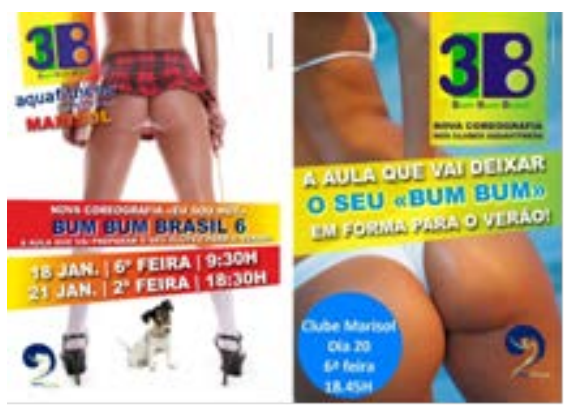

Figura 1 - peças publicitárias divulgadas pela Internet do programa 3B - Bum Bum Brasil voltado para a mulher portuguesa.

Estas observações levaram-nos a pensar no que Portugal anda a importar do Brasil. Há, no nosso entendimento, uma reconstrução da imagem de uma mulher portuguesa mais globalizada e menos virtuosa e, provavelmente, um novo mercado a ser vislumbrado, que inclui serviços e produtos que visam enaltecer a beleza, a preocupação com a aparência e que acabam por objetificar e erotizar o corpo feminino. No entanto, deixamos esta questão para estudos futuros.

A moldura teórica do trabalho parte do conceito de Walter Lippmann que afirma: "Na maior parte dos casos nós não vemos em primeiro lugar, para então 
definir, nós definimos primeiro e então vemos. Na confusão brilhante, ruidosa do mundo exterior, pegamos o que nossa cultura já definiu para nós, e tendemos a perceber aquilo que captamos na forma estereotipada para nós por nossa cultura." (LIPPMANN; 2008, p.85)

O trabalho de Luciana Pontes veio acrescentar, ao pensamento de Lippmann, o conceito de estereótipo da mulher brasileira que habita o imaginário português, já que o seu trabalho trata da exotização das mulheres imigrantes brasileiras em Lisboa. Segundo a autora, a imagem da mulher brasileira acaba por ser constituída por atributos de "brasilidade", que estão relacionados com a etnicidade e a morenidade que estão presentes em vários discursos que tratam de episódios relacionados com as prostitutas brasileiras em Portugal (PONTES; 2004, p.248 e 249). No entanto, na análise do nosso corpus não identificamos "morenidade" como uma característica de brasilidade.

Consideramos, também, o que Igor José de Renó Machado conceitua como "mercado da alegria" que "se refere aos empregos que envolvem a animação (como músicos e dançarinos) e também o atendimento ao público (garçons, atendentes de comércio em geral) (MACHADO; 2004, p.260).

Pudemos perceber, a partir das leituras iniciais, que a atribuição de uma hipersexualidade à mulher brasileira pela sociedade portuguesa é real, o que nos levou a perguntar: quais seriam os motivos para tal conceito? Fomos investigar, então, na História, as origens para a construção do conceito que determinava às mulheres brasileiras uma pretensa hipersexualidade. Foi, então, a historiadora Mary Del Priori e o historiador Ronaldo Vainfas que nos forneceram os subsídios para entender as origens da atribuição de um extremo sexy-appeal à mulher brasileira.

Uma vez apropriados das questões relativas ao conceito de estereótipo, de que nos fala Lippmann, das pesquisas relacionadas ao estereótipo da mulher brasileira em Portugal e dos fatos históricos que deram origem a esse conceito, sentimos a necessidade de buscar autores que contribuíssem no que diz respeito ao entendimento de identidade. No entanto, como analisamos imagens e procuramos nas imagens, por nós analisadas, questões que representassem visualmente características de brasilidade, chegamos à conclusão de que precisávamos de ferramentas que nos auxiliassem na interpretação dessas imagens e não no conceito de identidade de que nos falam as Ciências Sociais. Por se tratar de uma pesquisa que se insere no campo do Design Gráfico, nada mais lógico que buscar subsídios teóricos em autores que tratam de questões relativas à identidade visual.

Com esse intuito, recorremos aos conceitos de identidade visual de autores como Gilberto Strunck e Maria Luísa Péon. A partir dessas leituras, pudemos perceber que as características de brasilidade representadas nas imagens analisadas, estavam relacionadas com as aparências das mulheres representadas, ou seja, com as suas exterioridades. Segundo Luiz Antonio Coelho, pessoa e objeto "são equiparados (pessoa aqui equivale a objeto porque é abordada em sua forma, passível de projetação da realidade externa como qualquer objeto)". (COELHO; 2011, p.157 e 158)

Sérgio Luiz Silva também contribuiu para que entendêssemos que "mulher brasileira" é, de certa forma, uma marca e, portanto, as suas representações são capazes de demonstrar determinados "valores" atribuídos à marca "mulher brasileira".

Após a apropriação dos conceitos relativos às questões ligadas à identidade de marca e termos percebido que "mulher brasileira" pode ser considerada um produto 
e, portanto, passível de ser "vendido" como tal, fomos procurar conceitos que nos auxiliassem a compreender a "linguagem".

Partimos, então, do conceito de Barthes que diz que "(...) o que define uma linguagem não é o que ela diz, é o modo como diz" (BARTHES; 2005, p.68). Fomos buscar no dialogismo de Bakhtin o conceito de interação entre consciências, a individual e uma outra, que acabam por fazer com que os signos emerjam (BAKHTIN; 1999, p.34) e que definem a simbolização realizada pelos seres humanos como um processo de interação social.

O pensamento de Foucault contribuiu com as questões relativas ao discurso, pois o discurso faz parte da linguagem e a linguagem representa. Discurso é uma prática social de produção de textos, sejam os textos de qualquer natureza; são textos, são discursos e, por serem discursos, estão impregnados de ideologias. O corpus é constituído de textos imagéticos, portanto, "lemos" imagens.

Fomos buscar, também, em José Machado Pais, o conceito de sociologia do quotidiano que acaba por facilitar o entendimento acerca de processos interpretativos, pois segundo o autor, "A interpretação é sempre construção". (PAIS; 2007, p.70)

A antropologia visual que, segundo Malisse, diz respeito ao "modo como o mundo é visto e de quais são suas imagens" que, uma vez filtradas, acabam por constituir "o consenso visual da sociedade estudada", forneceu subsídios para uma leitura mais ampla do corpus. Segundo o mesmo autor, "a antropologia visual deve permitir o estudo das manifestações visuais de uma cultura (expressões faciais, movimentos, dança, exercícios físicos) e também dos seus aspectos pictóricos (televisão, imprensa, publicidade, objetos, arte)". Como o corpus da pesquisa foi retirado da mídia impressa, assim como as outras imagens não pertencentes ao corpus, mas que forneceram suporte ao estudo também o foram, as contribuições de Malisse foram bastante pertinentes para o trabalho.

E por fim, outra área do conhecimento utilizada como moldura teórica da investigação, diz respeito a questões relativas à cultura-mundo e à cultura-visual (SMITH; 1999, p.183). Anthony Smith contribuiu com conceitos que demonstram que "cultura" deve ser falada no plural, ou seja, "culturas" e que "cultura global" é algo que não faz sentido. Immanuel Wallerstein fala da "cultura" que define um grupo e que uma mesma pessoa faz parte de muitos grupos e por "conseguinte, cada pessoa participa de muitas "culturas". (WALLERSTEIN; 1999, p.41)

Nestor Garcia Canclini reconhece as "tendências globalizadoras, sobretudo nas indústrias culturais", mas afirma que "não tem sentido falar numa cultura global que substituiria as culturas nacionais". (CANCLINI; 2003, p.49)

Já Gilles Lipovetsky, que considera que estamos vivendo a época "hipermoderna", diz que a "cultura-mundo" "se tornou um setor econômico em plena expansão, a tal ponto considerável que se chega a falar, não sem razão, de 'capitalismo cultural'"'. (LIPOVETSKY; 2011, p.68)

Fomos beber do pensamento de José de Souza Martins, que tece considerações sobre a contribuição da "reflexão sociológica sobre a fotografia para desvendar aspectos do imaginário social e das mediações nas relações sociais" (MARTINS; 2008, p.35), o embasamento para demonstrar como a fotografia pode revelar muitas mensagens, inclusive opostas. Ao desconstruirmos uma imagem, buscamos compreendê-la e "compreendê-la para compreender a sociedade que por meio dela se propõe e se imagina". (Ibid., p.51) 
Sérgio Luiz Silva contribui com o conceito de classificação e categorização sociológicas dos elementos identitários do ato de "interpretar as representações estéticas das identidades e os conteúdos simbólicos contidos em imagens". O autor afirma ser essa uma forma de utilização das "imagens como um modelo de pronunciamento, uma narrativa visual por meio da qual valores estéticos e documentais são representados e passíveis de interpretação". (SILVA; 2007, p.611)

\subsection{A análise}

A partir do referencial teórico utilizado para o embasamento do estudo, as imagens pertencentes ao corpus da pesquisa foram analisadas. Levou-se em consideração um vasto conjunto de elementos que forneceram subsídios para desconstruir as imagens e extrair delas informações capazes de proverem dados que ajudassem a compreender, melhor, as sociedades que as produziram. Aqui referimos sociedades no plural, pois analisamos imagens produzidas no Brasil, que ao serem inseridas nas páginas das revistas generalistas portuguesas, acabam por ser ressignificadas.

São tratadas, também, questões relativas à construção de identidade de gênero. Simone de Beauvoir já dizia em 1949: "ninguém nasce mulher, torna-se mulher". Grupos sociais diferentes estabelecem papéis sociais diferentes, logo, ser mulher no Brasil, difere de ser mulher em Portugal.

O Brasil é um país tropical com uma longa costa, o que proporciona condições para que os corpos estejam em maior evidência e mais desnudos. No Brasil, a exposição do corpo e a valorização das formas desse corpo, ditadas pela indústria cultural, é, de certa forma, natural. O corpo brasileiro pode ser considerado como "hipervisível", enquanto o corpo português definimos como "invisível", inexistente.

Mas não são só as diferenças relativas aos corpos e à percepção desses corpos que fazem com que o "ser mulher" no Brasil seja diferente do "ser mulher" em Portugal. Há uma construção histórica que acaba por explicar muitas das diferenças. As relações miscigenadas estabelecidas pelos colonizadores portugueses com as indígenas brasileiras e as negras africanas escravizadas e as origens do conceito de hipersexualização da mulher brasileira são prova disso, assim, foi preciso visitar a história do Brasil Colônia. Pudemos, assim, perceber a partir de leituras que tratavam de questões relativas à história da sexualidade no Brasil e em Portugal, os fatos e os contextos que acabaram por definir comportamentos e formas de estar no mundo bastante diferentes - os comportamentos são construídos historicamente.

Comparar a imagem de uma mulher brasileira, no caso, a atriz Juliana Paes, com a imagem de uma mulher portuguesa, a miss portuguesa Marina Rodrigues, publicadas na mesma página, da mesma edição da revista Sábado no 248, fez-nos perceber o quanto essas representações eram diferentes e o quanto uma atribuía à outra características opostas. A sensualidade de Juliana Paes confirma o recato de Marina Rodrigues, no entanto, o recato de Marina Rodrigues atribui a Juliana Paes uma hipersexualidade. Lógico que são imagens construídas em contextos diferentes, mas, ao serem inseridas na mesma página, acabam por ser ressignificadas. 

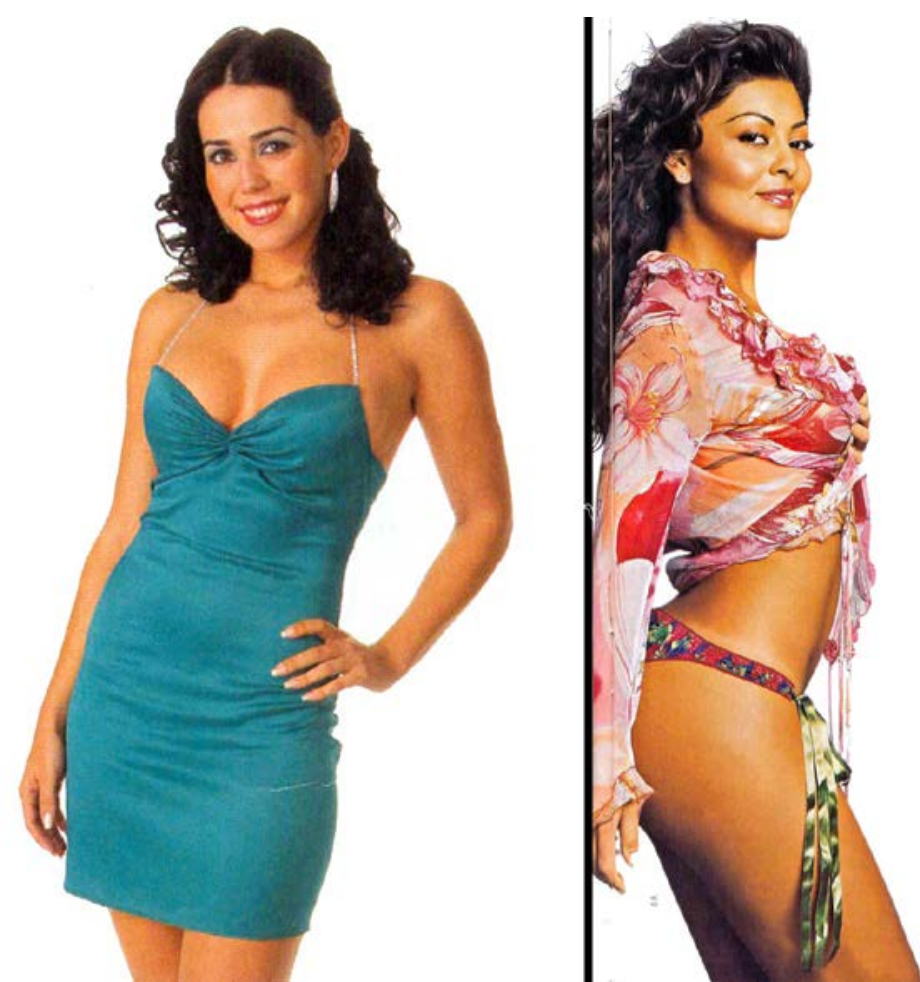

Figura 2 - revista Sábado no 248 - edição de 29 de janeiro a 4 de fevereiro de 2009 - p.24 e 25

Não pudemos deixar de citar os ciclos migratórios, pois acreditamos que são, também, responsáveis pela imagem portuguesa acerca da mulher brasileira e que, logicamente, contribuem para o estereótipo da mulher brasileira que habita o imaginário português e que, a nosso ver, está em mutação. Se no final da década de 90 as brasileiras, que migravam para Portugal, iam para trabalhar no que Machado Paes conceitua como "mercado da alegria" e acabavam por se prostituir, podemos dizer que hoje o cenário é outro. A crise econômica em Portugal, por oposição ao crescimento da economia brasileira, fez com que muitas dessas mulheres voltassem para o Brasil, no entanto, há um grande fluxo de estudantes brasileiros indo para Portugal. Entre eles, estudantes de graduação, do programa Erasmus, estudantes de mestrado e estudantes de doutorado que vão, inclusivamente, financiados pelo governo brasileiro.

O novo movimento migratório de brasileiros para Portugal, possuidores de um nível sócio econômico e cultural de outra tipologia dos imigrantes do final da década de 90, acaba por modificar, ainda que timidamente, a imagem da mulher brasileira que habita o imaginário português. A crise econômica em Portugal e a visualidade do Brasil como uma potência emergente contribuíram para estabelecer o Brasil como um destino para negócios e para "se bem viver".

$\mathrm{Na}$ pesquisa foi considerado o significado de representação como "idéia ou imagem que concebemos do mundo ou de alguma coisa", segundo Houaiss, ou mesmo como Luiza Novaes descreve "uma representação é meramente o que representa, por exemplo, um signo ou símbolo, um substituto, um exemplar". (NOVAES; 2008, p.47)

A partir de leituras como A produção da crença: contribuição para uma economia dos bens simbólicos (2004), de Pierre Bourdieu, pudemos considerar que representações constituem um papel deveras importante no nosso entendimento acerca do "nosso lugar" na sociedade em que vivemos. E, aqui, foi importante verificar o que cada uma das sociedades em questão, a brasileira e a portuguesa, estabelecem 
como representações do "lugar" de cada um. Salazar afirmava: "um lugar para cada um e cada um no seu lugar".

Não há como negar que sociedades distintas estabelecem lugares distintos para os indivíduos que constituem os seus grupos sociais. Logo, podemos dizer que cada sociedade também estabelece um papel para o feminino e outro para o masculino. Esses papéis podem divergir de sociedade para sociedade, mas não conhecemos uma sociedade em que ao feminino e ao masculino sejam determinados os mesmos papéis. É fato que existem diferenças. Logo, cada sociedade tem "um lugar para a mulher" e "um lugar para o homem" e, evidentemente, as representações acerca dos papéis a serem desempenhados também são diferentes.

Uma vez observadas as questões referentes às diversas formas de representar o feminino e o masculino, pudemos identificar como alguns critérios, que estabelecem essas representações, acabam por determinar, a elas, conteúdos ideológicos. Partimos, então, para um estudo sobre a linguagem.

Consideramos linguagem como um sistema de comunicação que se pode dar de diversas formas - verbal, visual, gestual, entre outras. Muitas vezes uma forma complementa a outra como, por exemplo, a verbal associada à gestual, ou, no caso das leituras que fazemos das imagens do corpus, a visual associada à gestual. Mas é claro que a linguagem pressupõe um código e que cada grupo é detentor de um repertório diferente. Sendo assim, grupos possuidores de referenciais diferenciados decodificam representações de formas diferentes, isto é, segundo os seus mundos referenciais.

Partindo dos conceitos aqui apresentados acerca de representação e linguagem, pudemos verificar que as imagens de celebridades/atrizes brasileiras concebidas e produzidas no Brasil, ao serem inseridas nas páginas das revistas generalistas portuguesas, acabam por ser ressignificadas e colaboram na construção do conceito de brasilidade presente em Portugal.

Imagem é considerada um elemento de linguagem e está associada ao que é capaz de evocar nos sujeitos. São muitas as imagens referentes ao conceito de brasilidade que circulam nas diversas mídias em Portugal. Há as imagens construídas e produzidas no Brasil e exportadas para serem veiculadas em terras lusitanas, há as que os portugueses "importam" e há as que os próprios portugueses constroem a partir do seu entendimento acerca de características de brasilidade.

Imagens são signos visuais e necessitam de ser olhadas como tal, pois produzem significado, constroem e reconstroem identidades. $E$, se representam valores e sentidos, acabam, também, por definir conceitos de brasilidade. $O$ trabalho realizou-se através de uma análise de discurso de representações midiáticas retiradas de revistas generalistas (noticiosas) portuguesas.

O corpus foi retirado das revistas Focus e Sábado entre os meses de setembro de 2010 e março de 2011. E foi constituído por vinte e seis imagens inseridas em vinte e duas edições e possui imagens de vinte atrizes/celebridades brasileiras. Algumas atrizes/celebridades são encontradas nas duas revistas e há edições em que encontramos duas atrizes/celebridades na mesma página.

As imagens foram analisadas a partir de quatro categorias de análise por nós estabelecidas, após uma longa observação das imagens coladas, em ordem cronológica, em uma parede. As categorias definidas foram os atributos de brasilidade e as suas representações; a relação das imagens das atrizes/celebridades com outros 
elementos na página; as relações intertextuais e as questões referentes aos leitores e o seu potencial de relacionar os conteúdos a diversos níveis de significado.

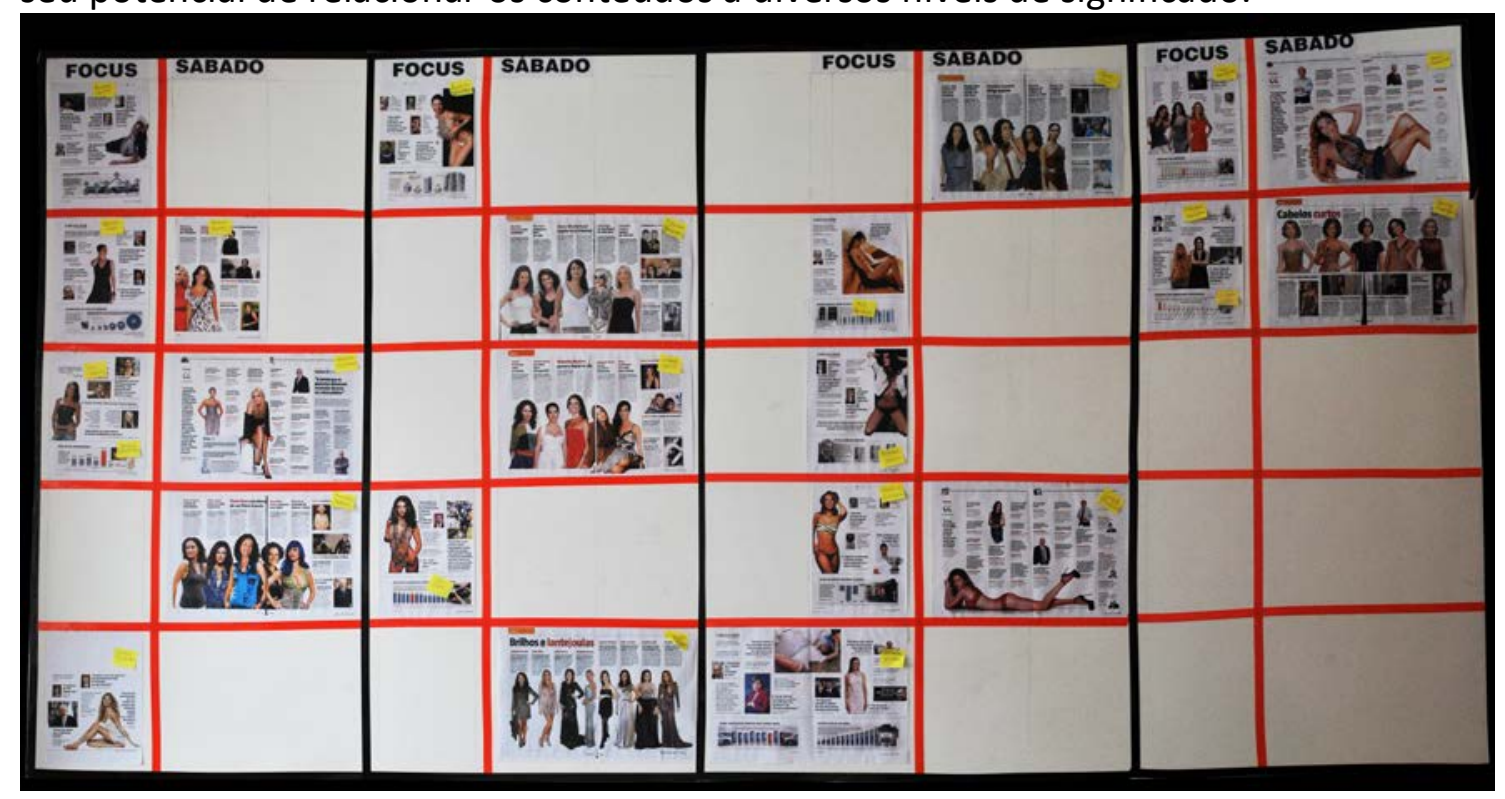

Figura 3 - páginas das revistas que formaram o corpus disponibilizadas na parede.

Sentimos, também, a necessidade de ir buscar, na teoria de Panofsky (1986), os três níveis de leitura de uma imagem: o pré-iconográfico, o iconográfico e o iconológico. Embasamos a análise nas questões que tratam das "histórias dos sintomas culturais ou símbolos", de que nos fala Panofsky e, também, no pensamento de Bourdieu (2004) quando nos fala do habitus, "a identidade social define-se e afirma-se na diferença".

A partir das categorias de análise definidas no capítulo referente à metodologia, iniciamos a análise do corpus. No entanto, antes de olhar para as imagens e iniciar, realmente, a leitura e a desconstrução do material coletado, tornouse necessário o aprofundamento de alguns conceitos referentes a questões relativas a um maior entendimento acerca do que é uma imagem. Para isso, fomos buscar no pensamento de Belting e em sua visão antropológica "o que é uma imagem".

Fez-se necessário, também, uma reflexão acerca da possível virtualidade do conceito de estereótipo e das manipulações passíveis de serem realizadas nas imagens. Exemplos de verdadeiras aberrações foram utilizados e, na análise do corpus, sinalizados e verificados. Foi sinalizado, também, o que é importado para Portugal do Brasil e foi registrado que algumas dessas "importações" podem ser desenvolvidas em estudos futuros.

Ainda antes de entrar na análise do corpus, foi discutido o conceito de mídia primária, mídia secundária e mídia terciária segundo o conceito de Baitello e, a partir do seu pensamento, estabelecemos que o corpo, a indumentária e os adereços constitutivos das imagens analisadas são considerados como mídia secundária.

Ao nos depararmos com nomenclaturas como "erotização" e "hipersexualização", muito utilizadas na tese, fez-se necessário um aprofundamento acerca desses conceitos. Foi importante ir buscar o significado etimológico da palavra erótico, que advém do conceito de Eros. Ao realizarmos esse aprofundamento, percebemos que a hipersexualização acaba por ser um reducionismo da erotização e, 
acreditando ser o estereótipo também um reducionismo, acabamos por definir o conceito de hipersexualização como o apropriado para a leitura das imagens do corpus.

As imagens foram analisadas cronologicamente, ou seja, a revista Focus e a revista Sábado em simultâneo. O que determinou essa sequência foi o fato de encontrarmos uma mesma atriz/celebridade brasileira nas duas revistas em uma mesma semana. As imagens foram lidas a partir das características de análise estabelecidas pela metodologia desenvolvida e embasadas nos conceitos de préiconografia, iconografia e iconologia de que nos fala Panofsky. O pensamento de Bourdieu, conceito de habitus, "a identidade social define-se e afirma-se na diferença" (2004), também foi um referencial.

As características de análise foram as seguintes:

1 - os atributos de brasilidade e suas representações. São elementos como a exposição do corpo, expressão facial e linguagem corporal, sensualidade, erotização e indumentária;

\section{2 - a relação das imagens das atrizes/celebridades com outros elementos na}

página. Questões como posição da imagem na página, destaque ou não destaque dado à atriz/celebridade, relação do tamanho da imagem em comparação com o tamanho das outras imagens e a presença, ou não presença, de elementos gráficos que compõem as imagens;

3 - relações intertextuais. Dizem respeito a eventos, novelas e exposição em outras mídias que, de certa forma, justifica a presença da atriz/celebridade na edição da revista em questão;

4 - o leitor e seu potencial de relacionar os conteúdos a diversos níveis de significado. São questões relativas à possível indução de uma interpretação, pelo leitor, de elementos que buscam confirmar o estereótipo da mulher brasileira, ou seja, uma mulher hipersexualizada e erotizada.

A metodologia utilizada alcançou o objetivo principal do trabalho, que era contribuir para uma leitura mais eficaz de representações midiáticas a partir do desenvolvimento de um mecanismo de interpretação do universo imagético que, de certa forma, buscasse consolidar um conjunto de meios de decodificação de imagens e de produção de significados. A partir das categorias de análise estabelecidas, do pensamento dos autores que embasaram as escolhas feitas e da análise realizada, pudemos alcançar conclusões que acabam por confirmar a hipótese inicial da pesquisa e que abrem possibilidades para pesquisas futuras.

Somente dez imagens de atrizes/celebridades brasileiras estampadas nas revistas Focus e Sábado pertencentes ao corpus podem ser consideradas como hipersexualizadas. Quando há atrizes/celebridades portuguesas estampadas juntamente com outras atrizes/celebridades internacionais na mesma página, ou a atriz/celebridade portuguesa ganha o maior destaque, seja pela localização na página ou pelo tamanho da sua imagem ou todas as imagens, acabam por ter a mesma importância.

Verificamos que Gisele Bündchen é a atriz/celebridade brasileira que "mais aparece", tendo encontrado três representações da Top Model brasileira nas vinte e duas páginas analisadas. Na maioria das páginas da revista Focus encontramos 
atrizes/celebridades brasileiras com o maior destaque na página, de forma a minimizar outros assuntos como economia, política e desportos, ou esportes como se diz no Brasil.

Interessante perceber que apesar da pesquisadora Luciana Pontes (2004) afirmar, em seu estudo acerca da exotização da mulher brasileira em Lisboa, que morenidade é um conceito relacionado com a brasilidade, não foi encontrada nenhuma imagem de uma atriz/celebridade brasileira representativa da raça negra. $A$ única atriz/celebridade passível de ser considerada da raça negra, Camila Pitanga, é representada como da raça branca.

Apesar de encontrarmos no corpus dez representações de atrizes/celebridades brasileiras hipersexualizadas, não podemos afirmar que hipersexualização seja um atributo de brasilidade geralmente presente em representações de mulheres brasileiras em Portugal. Porém, a análise do corpus aponta para atributos de brasilidade como: beleza, sensualidade, magreza, juventude, naturalidade em exibir o corpo e hipervisibilidade, atributos que, de certa forma, estão associados à hipersexualização.

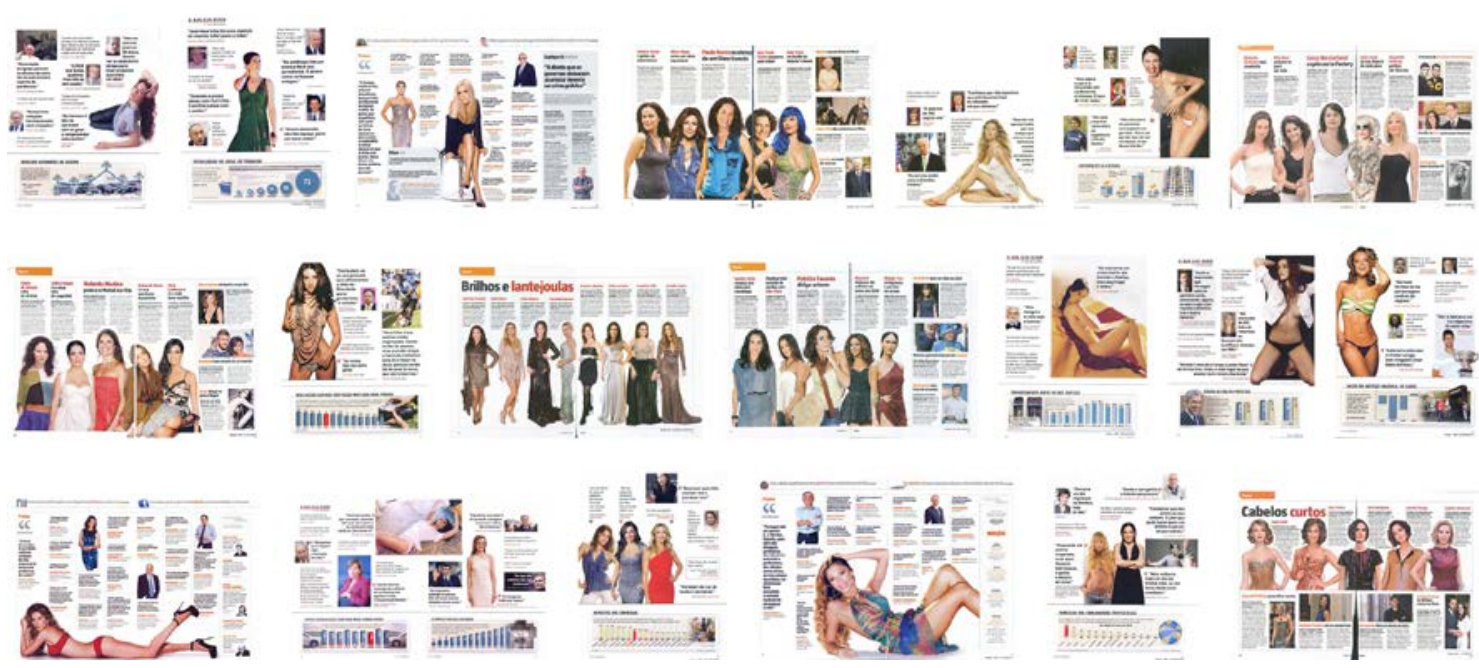

Figura 4 - páginas das revistas que formaram o corpus da pesquisa.

\section{CONCLUSÃO}

A partir da análise realizada, pudemos considerar que as imagens das atrizes/celebridades brasileiras foram ressignificadas, pois algumas das imagens estampadas nas páginas das revistas pertencentes ao corpus, não correspondiam às falas a elas atribuídas. As imagens e as falas não faziam parte de um mesmo evento ou contexto e acabavam por ressignificar a imagem e vice e versa.

A partir da análise realizada, a hipótese inicial da pesquisa foi confirmada. Sim, podemos considerar que há uma exotização atribuída à mulher brasileira capaz de consolidar uma pretensa virtuosidade à mulher portuguesa. Não foram encontradas representações de mulheres portuguesas hipersexualizadas como foram encontradas das brasileiras, se concordamos com Bourdieu que "a identidade social define-se e afirma-se na diferença" (2004), as mulheres brasileiras são exotizadas ao serem comparadas com as representações das mulheres portuguesas. 
A finalização deste trabalho apontou para algumas possibilidades de estudos futuros que deverão ser desenvolvidos a partir das conclusões tiradas em função, não só, da análise do corpus, mas também, de observações realizadas ao longo da investigação.

\section{REFERÊNCIAS}

BAKHTIN, Mikhail Mikhailovitch. Marxismo e filosofia da linguagem: problemas fundamentais do método sociológico na ciência da linguagem. São Paulo: Hucitec, 1999.

BARTHES, Roland. Inéditos, vol. 3: imagem e moda. São Paulo: Martins Fontes, 2005.

BELTING, Hans. Por uma antropologia da imagem. In: Concinnitas, ano 6, volume 1, número 8, julho 2005.

BOURDIEU, Pierre. A distinção crítica social do julgamento. São Paulo: Edusp; Porto Alegre: RS: Zouk, 2008.

CANCLINI, Néstor García. A globalização imaginada. São Paulo: Editora Iluminuras LTDA, 2003.

COELHO, Luiz Antonio L. Ator e identidade. In: Estudos de identidades: entre saberes e práticas. BASTOS, Liliane Cabral e LOPES, Luiz Paulo da Moita (orgs). Rio de Janeiro: Garamond, 2011.

LIPPMANN, Walter. Opinião pública. RJ: Vozes, 2008.

LIPOVETSKY, Gilles e SERROY, Jean. A cultura-mundo: resposta a uma sociedade desorientada. São Paulo: Companhia das Letras, 2011.

MACHADO, Igor José de Renó. Afetividade e poder entre os imigrantes brasileiros no Porto. In Cadernos Pagu (23), julho-dezembro de 2004, PP.257-278.

MARTINS, José de Souza. A fotografia e a vida cotidiana: ocultações e revelações. In: O visual e o quotidiano. CARVALHO, Clara; GUSMÃO, Neusa Mendes de e PAIS, José Machado. (organizadores). Lisboa: ICS. Imprensa de Ciências Sociais, 2008.

NOVAES, Luiza. Representação. In: Conceitos-chave em design. Luiz Antonio Luzio Coelho. (Org.). Rio de Janeiro; Teresópolis: Editora PUC-Rio; Novas Idéias, 2008, v. , p.46-47.

PAIS, José Machado. Sociologia da vida quotidiana: teorias, métodos e estudos de caso. Lisboa: ICS. Imprensa de Ciências Sociais, 2007.

PANOFSKY, E. "Iconografia e Iconologia: Uma introdução ao estudo da arte da Renascença". In: Significado nas Artes Visuais. Tradução: Maria Clara F. Kneese e J. Guinsburg. São Paulo: Perspectiva, 2ª ed., 1986, p. 47-65.

PONTES, Luciana. Mulheres brasileiras na mídia portuguesa. In: Cadernos Pagu (23), julho-dezembro de 2004, PP.229-256.

SILVA, Sérgio Luiz P. Cultura visual e afirmações identitárias: novos processos de reconhecimento social. In: Anais do II Seminário Nacional Movimentos Sociais, 
Participação e Democracia - 25 a 27 de abril de 2007, UFSC, Florianópolis, Brasil Núcleo de Pesquisa em Movimentos Sociais - NPMS.

SMITH, Anthony D. Para uma cultura Global? In: Cultura global: nacionalismo, globalização e modernidade. FEATHERSTONE, Mike (coord.). Petrópolis: Editora Vozes, 1999.

WALLERSTEIN, Immanuel. A cultura como campo de batalha ideológico do sistema mundial moderno. In: Cultura global: nacionalismo, globalização e modernidade. FEATHERSTONE, Mike (coord.). Petrópolis: Editora Vozes, 1999. 